\title{
Efeito residual da jitirana, flor-de-seda e mata-pasto no cultivo da rúcula em sucessão a beterraba
}

\section{Residual effect of scarlet starglory, roostertree and Senna obtusifolia in the cultivation of rocket in succession sugar beet}

\author{
Alany Moisa Bezerra de Almeida ${ }^{1}$, Paulo César Ferreira Linhares ${ }^{2}$, João Liberalino Filho ${ }^{3}$, Ana Paula Morais Neves ${ }^{4}$, Sérgio \\ Luiz Silva de Morais ${ }^{5}$
}

\begin{abstract}
Resumo: O efeito residual da adubação anterior em cultivos subsequente é de suma importância, uma vez que a fertilização do solo em uma atividade tão intensa, como a olericultura, aumentaria o custo de produção sempre que fosse implantada uma nova cultura. Este trabalho foi conduzido na Fazenda Experimental Rafael Fernandes, localizada no distrito de Alagoinha, zona rural de Mossoró-RN, no período de novembro a dezembro de 2011. Objetivou-se avaliar o efeito residual da jitirana, flor-deseda e mata-pasto no cultivo da rúcula em sucessão a beterraba. A beterraba foi plantada em parcelas de 1,2 x 1,2 m e adubado com espécies espontâneas, nas quantidades: 0,6;1,2; 1,8;2,4 e 3,0 $\mathrm{kg} \mathrm{m}^{-2}$ de canteiro. Após a retirada da beterraba, semearamse sementes de rúcula nas parcelas referente aos tratamentos acima citados. O delineamento experimental foi em blocos casualizados com três repetições, no esquema fatorial 5 x 3, sendo cinco quantidades e três tipos de adubos verdes (jitirana; flor-de-seda e mata-pasto). A cultivar de rúcula plantada foi a Cultivada. As características avaliadas foram: altura e número de folhas por planta, massa fresca, número de molho de rúcula e massa seca. Houve interação dos fatores estudados para massa fresca de rúcula e número de molhos. O efeito residual na quantidade de $3,0 \mathrm{~kg} \mathrm{~m}^{-2}$ de canteiro contribuiu para a massa fresca de rúcula da ordem de 762; 684 e $713 \mathrm{~g} \mathrm{~m}^{-2}$ de canteiro, equivalente a 6,0; 5,0 e 5,0 molhos de rúcula para jitirana, flor-de-seda e mata-pasto, respectivamente. Jitirana, flor-de-seda e mata-pasto são espécies promissoras para ser utilizadas como adubo verde na produção de hortaliças.
\end{abstract}

Palavras-chaves: Espécies espontâneas. Eruca sativa. Produção agroecológica.

\begin{abstract}
The residual effect of previous fertilization in subsequent crops is extremely important, since soil fertilization in such an intense activity, such as horticulture, increase the cost of production when it was implemented a new culture. This work was conducted at the Fazenda Experimental Rafael Fernandes, located in Alagoinha district, rural Mossoró-RN, in the period from november to december 2011. The objective was to evaluate the Residual effect of scarlet starglory, roostertree and Senna obtusifolia in the cultivation of rocket in succession sugar beet. The sugar beet was planted in $1.2 \mathrm{x} 1.2$ plots fertilized with me wild species, quantities: $0.6 ; 1.2 ; 1.8 ; 2.4$ and $3.0 \mathrm{~kg} \mathrm{~m}^{-2}$ site. After the withdrawal of beetroot, seeded rocket seeds in installments related to the above mentioned treatments. The experimental design was a randomized block with three replications, in a factorial 5 x 3, five quantities and three types of green manure (scarlet starglory; roostertree and Senna obtusifolia). The cultivar planted rocket was the cultivated. The characteristics evaluated were height and number of leaves per plant, fresh, arugula sauce number and dry matter. There was interaction of the factors studied for fresh pasta and arugula number of sauces. The residual effect on the amount of $3.0 \mathrm{~kg} \mathrm{~m}-2$ site contributed to the fresh weight of the order arugula 762; 684 and $713 \mathrm{~g} \mathrm{~m}-2$ site, equivalent to 6.0; 5.0 and 5.0 arugula dressings scarlet starglory, roostertree and Senna obtusifolia, respectively. Scarlet starglory, roostertree and Senna obtusifolia are promising species to be used as green manure in vegetable production.
\end{abstract}

Key words: Spontaneous species. Eruca sativa. Agroecological production.

\footnotetext{
*Autor para correspondência

Recebido para publicação em 02/04/2015; aprovado em 25/05/2015

${ }^{1}$ Mestranda em Sistemas Agroindustriais - UFCG/CCTA, Campus Pombal - PB, E-mail:alanymoisa1@ @otmail.com

${ }^{2}$ Eng $^{\circ}$ Agrônomo, D.Sc., PESQUISADOR DA UFERSA, Mossoró-RN. E-mail: paulolinhares@ufersa.edu.br; paulojitirana@yahoo.com.br

${ }^{32}$ Eng $^{\circ}$ Agrônomo, Prof. Da UFERSA, Mossoró-RN. E-mail:liberalino@ufersa.edu.br

${ }^{4}$ Mestranda em Sistemas Agroindustriais - UFCG/CCTA, Campus Pombal - PB, E-mail: anapaula_mn@ hotmail.com

${ }^{5}$ Aluno do $9^{\circ}$ período de Agronomia - UFERSA, Mossoró - RN, E-mail: sergioluizmorais@ hotmail.com
} 


\section{INTRODUÇÃO}

A rúcula é uma hortaliça herbácea, folhosa, anual, de ciclo curto, na qual pertence à família das Brassicáceae, originária da região mediterrânea e oeste da Ásia, cuja espécie mais utilizada no Brasil é a Eruca sativa Miller, entre as cultivares adaptadas a região nordeste estão a Cultivada e Folha Larga (LINHARES, 2009). Essa hortaliça possui sabor muito forte e picante, são ricas em vitaminas A e C, minerais como ferro, potássio e enxofre (FILGUEIRA, 2008). O seu uso na medicina acontece das suas distintas propriedades, tais como: digestiva, diurética, estimulante, laxativa e antiinflamatória. Seu consumo é na forma de saladas cruas e em pizzas (REGHIN et al., 2005). No Brasil, seu consumo é maior no sul e sudeste onde teve uma intensa colonização italiana, porém vem crescendo o consumo nas outras regiões (SILVA et al., 2008).

No Rio Grande do Norte, essa hortaliça vem sendo cultivado por pequenos agricultores que labutam na produção orgânica e utilizam com fonte de adubo, os estercos (bovino e caprino). No entanto, a utilização desse recurso encarece a produção, haja vista o produtor nem sempre tem em sua propriedade a disponibilidade desse material, o que muitas vezes obriga o mesmo adquirir de outros locais, aumentando os custos de produção. Dentro desse contexto, adubação verde surge como alternativa para substituição parcial ou total do uso de esterco (LINHARES et al., 2014).

De acordo com Fontanétti et al. (2004), a adubação verde com leguminosas reduz as amplitudes diárias da variação térmica e hídrica na camada superficial do solo, proporciona a formação e estabilização de agregados, melhorando as condições de aeração, infiltração e retenção de umidade. Além desses efeitos, a adubação verde tem sido usada como estratégia para minimizar os impactos provocados pelo uso intensivo do solo, aliando proteção e adubação (SILVEIRA et al., 2005). Segundo Linhares (2013) as espécies mais utilizadas como adubo verde são as leguminosas, pelo fato de produzirem quantidades de fitomassa verde e seca bastante lábil, o que favorece a relação carbono-nitrogênio $(\mathrm{C} / \mathrm{N})$ estreita.

Espécies espontâneas da caatinga de fácil ocorrência na região de estudo no período chuvoso, como jitirana (Merremia aegyptia L.) e mata-pasto (Senna uniflora) e durante todo ano, a flor-de-seda (Calotropis procera), tem sido utilizados como adubo verde na produção orgânica de hortaliças, contribuindo para o aumento em produtividade (LINHARES et al., 2009ab).

Alguns trabalhos foram desenvolvidos utilizando essas espécies como adubo verde. Sousa (2014) obteve produtividade do coentro da ordem de 1,$4 ; 1,6$ e $1,6 \mathrm{~kg} \mathrm{~m}^{-2}$, respectivamente para jitirana, flor-de-seda e mata-pasto. Testando quantidades de jitirana e tempos de decomposição na mesma cultura, encontraram na dose 15,6 $\mathrm{t} \mathrm{ha}^{-1} \mathrm{um}$ rendimento de $2403 \mathrm{~kg} \mathrm{ha}^{-1}$ (LINHARES et al., 2012a). Henriques et al. (2011), obtiveram produtividade de 26,3 g planta $^{-1}$, de rabanete avaliando o efeito residual da flor-deseda. Silvestre et al. (2012), avaliando o desempenho agronômico do coentro fertilizado com mata-pasto, observaram que o melhor desempenho foi obtido na quantidade de $15,6 \mathrm{t} \mathrm{ha}^{-1}$ com quinze dias de incorporação.

Nesse sentido, um importante aspecto a ser considerado quando se estuda a produção orgânica de hortaliças, especialmente utilizando adubos verdes, é o efeito residual da adubação anterior na produtividade subsequente, uma vez que a fertilização do solo em uma atividade tão intensa, como a olericultura, aumentaria o custo de produção sempre que fosse implantada uma nova cultura.

Assim sendo, o presente estudo, teve como objetivo avaliar o efeito residual da jitirana, flor-de-seda e mata-pasto no cultivo da rúcula em sucessão a beterraba.

\section{MATERIAL E MÉTODOS}

O experimento foi conduzido na Fazenda Experimental Rafael Fernandes, localizada no distrito de Alagoinha, zona rural de Mossoró-RN, no período de novembro a dezembro de 2011, em solo classificado como Latossolo Vermelho Amarelo Argissólico franco arenoso (EMBRAPA, 2006). Alagoinha está situada nas seguintes coordenadas: latitude 503'37'S e longitude de $37^{\circ} 23$ '50'W Gr, com altitude de aproximada de $72 \mathrm{~m}$, distando $20 \mathrm{~km}$ da cidade de MossoróRN. Segundo Thornthwaite, o clima local é DdAa', ou seja, semiárido, megatérmico e com pequeno ou nenhum excesso d'água durante o ano, e de acordo com Köppen é BSwh', seco e muito quente, com duas estações climáticas: uma seca, que geralmente compreende o período de junho a janeiro e uma chuvosa, entre os meses de fevereiro a maio (CARMO FILHO; ESPÍNOLA SOBRINHO; MAIA NETO, 1991).

Antes da instalação do experimento foram retiradas amostras de solo na profundidade de $0-20 \mathrm{~cm}$, as quais foram secas ao ar e peneirada em malha de $2 \mathrm{~mm}$, em seguida foram analisadas, obtendo-se os seguintes resultados: $\mathrm{pH}$ (água $1: 2,5)=6,5 ; \mathrm{Ca}=1,1 \mathrm{cmol}_{\mathrm{c}} \mathrm{dm}^{-3} ; \mathrm{Mg}=0,6 \mathrm{cmol}_{\mathrm{c}} \mathrm{dm}^{-3} ; \mathrm{K}=$ $0,11 \mathrm{cmol}_{\mathrm{c}} \mathrm{dm}^{-3} ; \mathrm{Na}=0,10 \mathrm{cmol}_{\mathrm{c}} \mathrm{dm}^{-3} ; \mathrm{P}=12,0 \mathrm{mg} \mathrm{dm}$ extrator Mehlich ${ }^{-1}$ e M.O. $=0,55 \%$. Inicialmente foi instalado um experimento com beterraba, cuja a incorporação do material orgânico foi aos 15 dias antes do plantio (SILVESTRE et al. 2012).

O delineamento experimental utilizado foi o de blocos completos ao acaso com os tratamentos arranjados em esquema fatorial $5 \times 3$, com três repetições. Os tratamentos consistiram na combinação de cinco quantidades de adubos verdes em efeito residual $\left(0,6 ; 1,2 ; 1,8 ; 2,4\right.$ e $3,0 \mathrm{~kg} \mathrm{~m}^{-2}$ de canteiro). Com três tipos de adubos verdes (jitirana, flor-deseda e mata-pasto).

As parcelas tinham $1,2 \times 1,2 \mathrm{~m}$ e comportavam seis linhas longitudinais de semeadura, sendo considerada útil às quatro linhas centrais, área total das parcelas foi de $1,44 \mathrm{~m}^{2} \mathrm{e}$ a área útil de $0,80 \mathrm{~m}^{2}$, contendo 80 plantas na área útil.

Plantou-se a rúcula, cultivar Cultivada, em semeadura direta no dia 15/11/2011, fazendo-se o desbaste aos sete dias após a emergência (DAE), deixando uma planta por cova no espaçamento de $0,20 \times 0,05 \mathrm{~m}$, perfazendo uma população de 700.000 plantas ha $^{-1}$, correspondendo a $70 \%$ da área, já que os espaços entre os canteiros, locais transitáveis, perfazem $30 \%$. Foram realizadas capinas manuais, com auxílio de enxadas e as irrigações foram efetuadas por microaspersão, com turno de rega diária parcelada em duas aplicações (manhã e tarde), fornecendo-se uma lâmina de água em média de $8 \mathrm{~mm} \mathrm{dia}^{-1}$.

As espécies espontâneas foram coletadas da vegetação nativa nas proximidades do campus da UFERSA, no início do período da floração, quando a planta apresenta o máximo de concentração de nutrientes (Figura 1 a 3). Depois triturados em máquina forrageira, em fragmentos de 2 a $3 \mathrm{~cm}$ de 
diâmetro, secos ao sol, em seguida armazenados em sacos de ráfia com teor de umidade de $12 \%$; $10 \%$ e $15 \%$ para jitirana, flor-de-seda e mata-pasto, respectivamente. Por ocasião da instalação do experimento, foram retiradas cinco amostras para análise, cuja concentração química de $\mathrm{N}$; $\mathrm{P}$ e $\mathrm{K}$ para jitirana foram de 24,6 $\mathrm{g} \mathrm{kg}^{-1}$ de nitrogênio; $10,5 \mathrm{~g} \mathrm{~kg}^{-1} \mathrm{de}$ fósforo e 11,3 $\mathrm{g} \mathrm{kg}^{-1}$ de potássio. Para flor-de-seda de $20,7 \mathrm{~g}$ $\mathrm{kg}^{-1}$ de nitrogênio; 10,0 $\mathrm{g} \mathrm{kg}^{-1}$ de fósforo e $28,9 \mathrm{~g} \mathrm{~kg}^{-1} \mathrm{de}$ potássio. Para o mata-pasto foi de $19,6 \mathrm{~g} \mathrm{~kg}^{-1}$ de nitrogênio; $10,0 \mathrm{~g} \mathrm{~kg}^{-1}$ de fósforo e $10,6 \mathrm{~g} \mathrm{~kg}^{-1}$ de potássio. Quantificados e incorporados na camada de $0-20 \mathrm{~cm}$ do solo nas parcelas experimentais referente a cada tratamento.

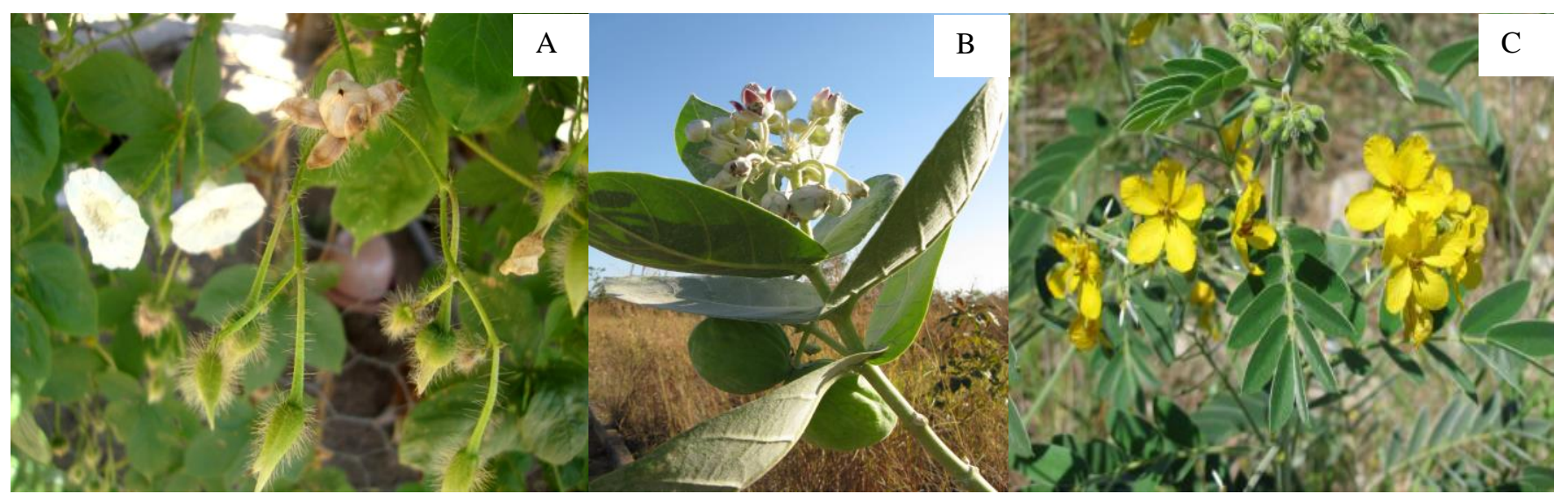

Figura 1- (A) Representação gráfica da jitirana (Merremia aegyptia); (B) flor-de-seda (Calotropis procera); (C) mata-pasto (Senna obtusifolia), espécie espontânea do bioma caatinga. UFERSA, Mossoró-RN, 2011.

A colheita foi realizada aos trinta e cinco dias após a semeadura (20/12/2011). Logo após a colheita, as plantas foram transportadas para o Laboratório de Pós-Colheita de Hortaliças do Departamento de Ciências Vegetais da UFERSA, onde foram analisadas.

Foram avaliadas as seguintes características: altura de planta (altura de planta foi tomada de uma amostra de vinte plantas por parcela medindo-se a altura desde o nível do solo até a inflexão das folhas, utilizando régua graduada em centímetros e expressa $\mathrm{cm}$ planta $^{-1}$ ); número de folhas por planta (número de folhas consistiu da contagem em uma amostra de vinte plantas e expresso em termos de média); massa fresca de rúcula (massa fresca de rúcula foi tomada de todas as plantas da área útil, cortadas em torno de dois centímetros de altura e pesadas em balança de precisão de 1,0 $\mathrm{g}$, expressa em $\mathrm{g} \mathrm{m}^{-2}$ de canteiro); massa seca de rúcula (massa seca foi obtida pela pesagem em balança eletrônica com precisão para $1,0 \mathrm{~g}$. Sua secagem foi realizada em estufa de aquecimento com ar forçado a $65^{\circ} \mathrm{C}$, até massa seca constante e expressa em $\mathrm{g} \mathrm{m}^{-2}$ de canteiro); número de molhos de rúcula (Considerou-se um molho de rúcula da ordem de $130 \mathrm{~g}$ em média, de acordo com o peso do molho de rúcula comercializado nas gondolas de supermercado na região de Mossoró-RN, para tanto, dividiu-se a quantidade obtida em $\mathrm{m}^{-2}$ de canteiro por $130 \mathrm{~g}$ e expressa em unidades $\mathrm{m}^{-2} \mathrm{de}$ canteiro).

Análises de variância para as características avaliadas foram realizadas através do aplicativo ESTAT (KRONKA; BANZATO, 1995). Para o fator quantidade, o procedimento de ajustamento de curva de resposta foi realizado através do Software Table Curve (JANDEL SCIENTIFIC, 1991), e, para o fator qualitativo, utilizou-se o teste de Tukey ao nível de 5\% de probabilidade para se fazerem as comparações entre os tipos de adubos verdes.

\section{RESULTADOS E DISCUSSÃO}

Não se observou interação das quantidades e tipos de adubos verdes para altura e número de folhas de rúcula e massa da matéria seca, com exceção de massa fresca e número de molhos de rúcula (Tabela 1).

A adição de material orgânico no solo, como resíduos de espécies espontâneas da caatinga é de fundamental importância para a manutenção do potencial produtivo do solo, pela adição de elementos essências ao crescimento, como o nitrogênio, o elemento mais abundante entre as espécies utilizadas, o que contribuiu provavelmente não só para a cultura da beterraba, mas foi responsável em promover condições edáficas satisfatória para um segundo cultivo.

Para altura, houve acréscimo médio de $6,0 \mathrm{~cm}_{\text {planta }}{ }^{-1}$ entre a menor quantidade de adubo verde $\left(0,6 \mathrm{~kg} \mathrm{~m}^{-2}\right.$ de canteiro) e a maior $\left(3,0 \mathrm{~kg} \mathrm{~m}^{-2}\right.$ de canteiro), incorporado ao solo, com valor médio de $20,2 \mathrm{~cm}$ planta $^{-1}$ na quantidade 3,0 $\mathrm{kg} \mathrm{m}^{-2}$ de canteiro de adubos verdes (Figura 2). Em relação aos tipos de adubos verdes, a jitirana foi superior estatisticamente à flor-de-seda e mata-pasto, com valores médios de 20,6; 18,4 e 18,2 cm planta ${ }^{-1}$, respectivamente (Tabela 2). O valor observado foi superior ao encontrado por Linhares et al. (2009a), correspondendo a 18,40 cm planta ${ }^{-1}$, avaliando períodos de incorporação do mata-pasto (Senna uniflora) na cultura da rúcula. 
Tabela 1. Valores de F para altura de planta (AT), expresso em $\mathrm{cm}_{\text {planta }}{ }^{-1}$, número de folhas por planta (NF), expresso em termos de média, massa fresca de rúcula (MFR), expresso em $\mathrm{kg} \mathrm{m}^{-2}$ de canteiro, número de molhos de rúcula (NMR), expresso em unidades $\mathrm{m}^{-2}$ de canteiro e massa seca de rúcula (MSR), expresso em $\mathrm{kg} \mathrm{m}^{-2}$ de canteiro. UFERSA, Mossoró-RN, 2011.

\begin{tabular}{|c|c|c|c|c|c|c|}
\hline Causas de Variação & GL & $\mathbf{A T}$ & NF & MFR & NMR & MSR \\
\hline Quantidades de adubos verdes (A) & 4 & $42,14^{* * *}$ & $35,39^{* * *}$ & $37,55^{\text {*** }}$ & $87,00^{* * *}$ & $26,39^{* * *}$ \\
\hline Tipos de adubos verdes (B) & 2 & $16,08^{* *}$ & $0,57^{\text {n.s }}$ & $9,58^{* *}$ & $76,05^{* *}$ & $0,57^{\mathrm{n} . \mathrm{s}}$ \\
\hline A X B & 8 & $1,26^{\mathrm{ns}}$ & $0,39^{\mathrm{ns}}$ & $13,89^{* *}$ & $26,27^{* *}$ & $1,58^{\mathrm{ns}}$ \\
\hline Tratamentos & 14 & $10,31^{* *}$ & $26,64^{* *}$ & $14,96^{* *}$ & $52,40^{* *}$ & $16,64^{\mathrm{ns}}$ \\
\hline Blocos & 2 & $6,05^{* *}$ & $4,84^{*}$ & $6,22^{* *}$ & $2,01^{\text {n.s }}$ & $4,84^{*}$ \\
\hline Resíduo & 28 & --- & ------- & -------- & ------ & ----------- \\
\hline $\mathrm{CV}(\%)$ & $\begin{array}{cl}--- \\
\end{array}$ & 8,03 & 8,47 & 11,58 & 8,20 & 11,45 \\
\hline
\end{tabular}

$=\mathrm{P}<0,01 ; *{ }^{*}=\mathrm{P}<0,05 ;{ }^{\mathrm{ns}}=\mathrm{P}>0,05$

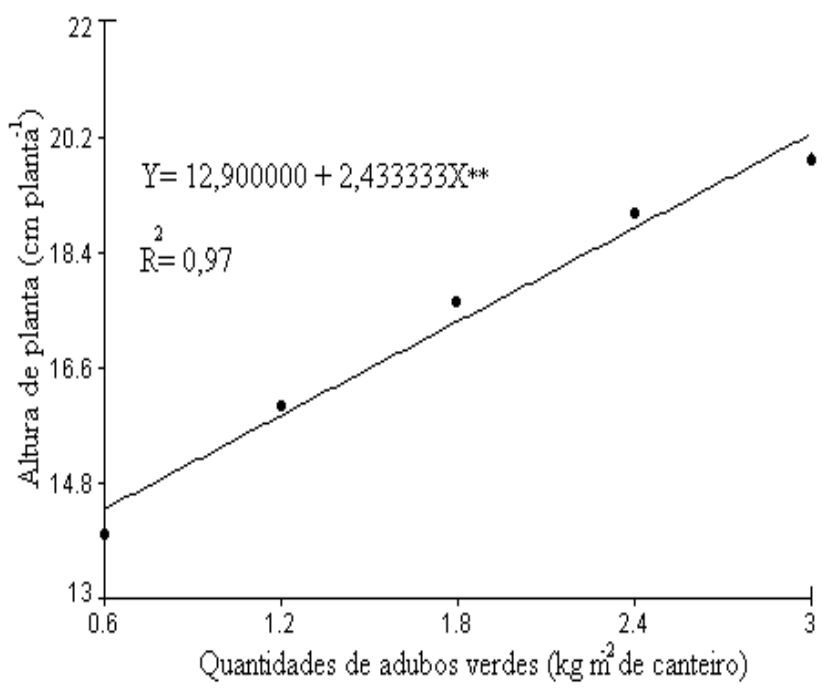

Figura 2. Altura de planta de rúcula sob diferentes quantidades de adubos verdes. UFERSA, Mossoró-RN, 2011.

Evidenciou-se uma resposta linear para a produção de folhas, na qual o número médio de 11,6 folhas planta $^{-1}$ foi obtido na quantidade de $3,0 \mathrm{~kg} \mathrm{~m}^{-2}$ de canteiro de adubos verdes (Figura 3). Esse valor correspondeu a um acréscimo de quatro folhas planta $^{-1}$ entre a menor quantidade de adubos verdes $\left(0,6 \mathrm{~kg} \mathrm{~m}^{-2}\right.$ de canteiro). Entre os tipos de adubos

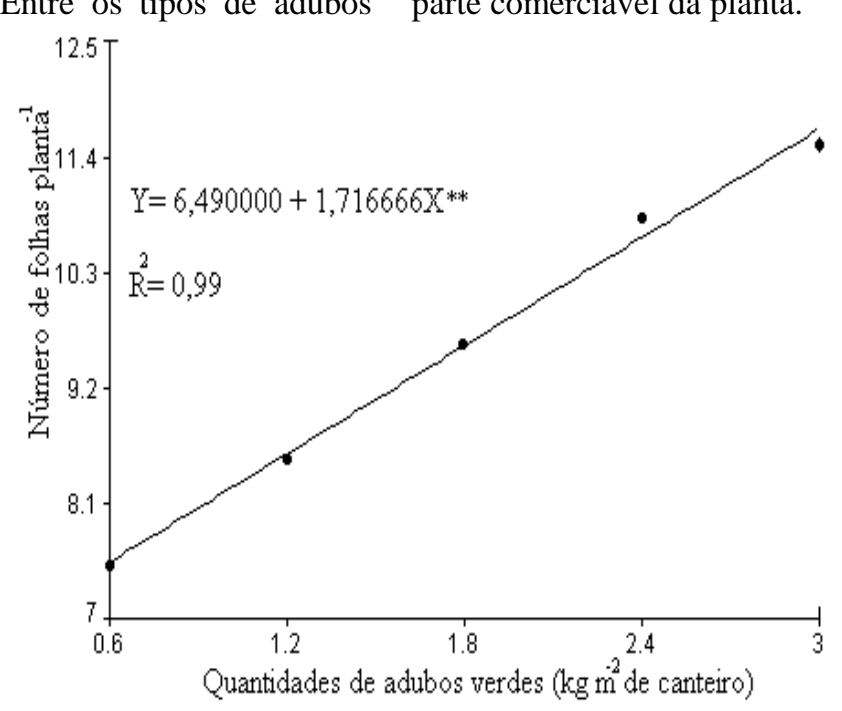

verdes não se observou diferenças significativas, com valores médios de 10,8; 10,0 e 10,0 para jitirana, flor-de-seda e matapasto, respectivamente (Tabela 2). O número de folhas em rúcula é de suma importância, tendo em vista ser esse órgão responsável pela realização da fotossíntese, além de ser a parte comerciável da planta. 
Desdobrando a interação do efeito residual das quantidades de adubos verdes dentro de cada tipo de adubo, observou-se massa fresca média de rúcula da ordem de 762; 684 e $713 \mathrm{~g} \mathrm{~m}^{-2}$ de canteiro para as espécies jitirana, flor-deseda e mata-pasto, respectivamente, na quantidade de $3,0 \mathrm{~kg}$ $\mathrm{m}^{-2}$ de canteiro de adubos verdes (Figura 4). Já, desdobrando os tipos de adubos verdes dentro das quantidades observou diferença estatística entre as quantidades de adubos verdes, com valores médios de 690; 600 e $610 \mathrm{~g} \mathrm{~m}^{-2}$ de canteiro para jitirana, flor-de-seda e mata-pasto, respectivamente, na quantidade 3,0 $\mathrm{kg} \mathrm{m}^{-2}$ de canteiro (Tabela 3). Esses valores diferiram dos encontrados por Solino et al. (2010) cultivando rúcula em espaçamento de $0,3 \times 0,1$ em plantio direto sob diferentes doses de composto e tipos de cobertura, encontraram produtividade de $8424 \mathrm{~kg} \mathrm{ha}^{-1}$, equivalente a 842 $\mathrm{g} \mathrm{m}^{-2}$ de canteiro sob vegetação espontânea associada à dose de $20,9 \mathrm{t} \mathrm{ha}^{-1}$ de composto, valor este superior à esta pesquisa. Essa superioridade em relação ao presente estudo deve-se possivelmente ao fato de Solino et al. (2010) está cultivando a rúcula em primeiro cultivo, além de que houve adição de composto associado as espécies espontâneas.

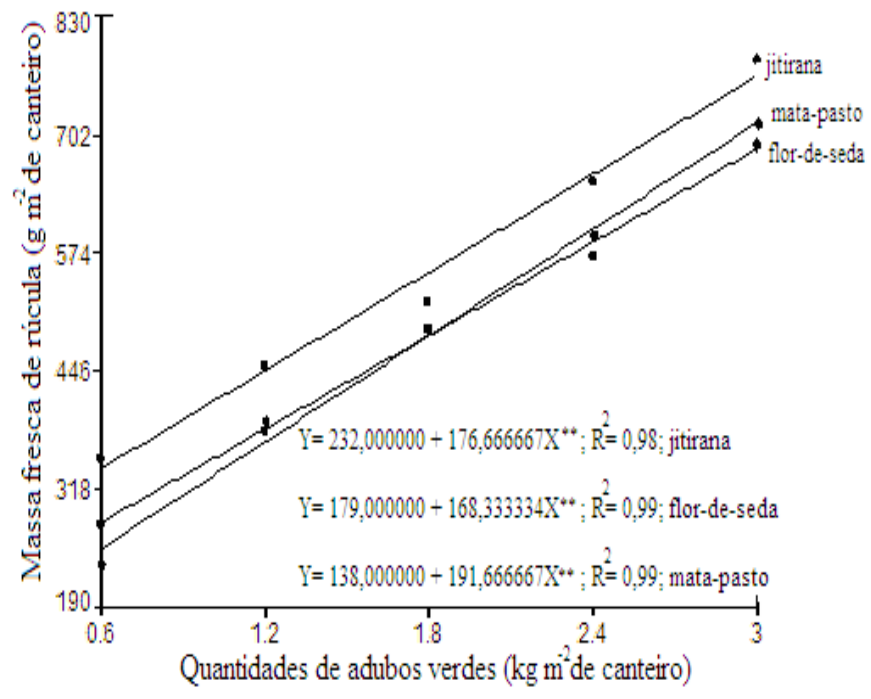

Figura 4. Massa fresca de rúcula sob diferentes quantidades de adubos verdes. UFERSA, Mossoró-RN, 2011.

Em relação ao número de molhos de rúcula, houve desdobramento das quantidades de adubos verdes dentro de tipos de adubos verdes com valor médio de 6,0; 5,0 e 5,0 molhos de rúcula $\mathrm{m}^{-2}$ de canteiro para jitirana, flor-de-seda e mata-pasto, respectivamente, na quantidade de $3,0 \mathrm{~kg} \mathrm{~m}^{-2}$ de canteiro de adubos verdes (Figura 5). Já, desdobrando os tipos de adubos verdes dentro das quantidades houve diferença estatística, com valores médios de 5,3; 4,6 e 4,7, respectivamente, para jitirana, flor-de-seda e mata-pasto na quantidade de $3,0 \mathrm{~kg} \mathrm{~m}^{-2}$ de canteiro (Tabela 4).

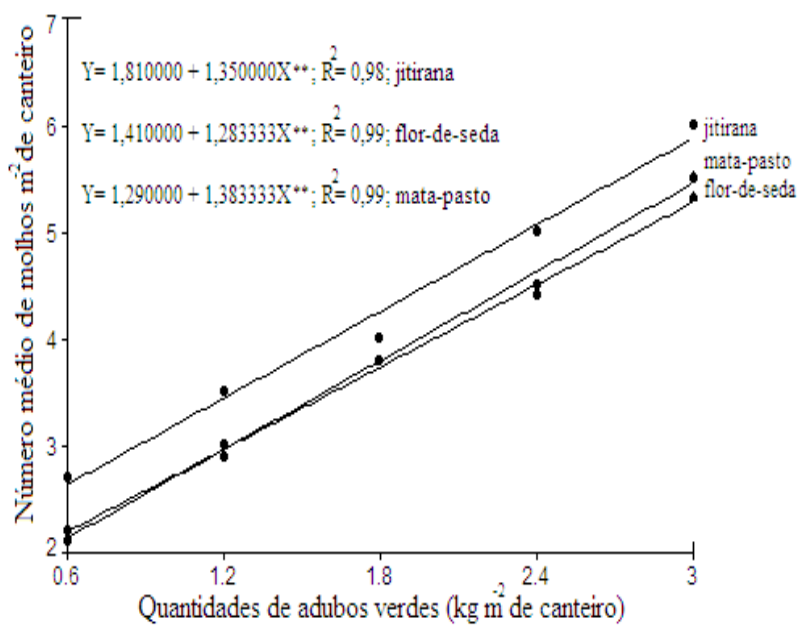

Figura 5. Número de molhos de rúcula sob diferentes quantidades de adubos verdes. UFERSA, Mossoró-RN, 2011.

Em relação à massa seca de rúcula foi observado acréscimo em função das quantidades de adubos verdes, com valor médio de $69 \mathrm{~g} \mathrm{~m}^{-2}$ de canteiro de massa seca de rúcula na quantidade de $3,0 \mathrm{~kg} \mathrm{~m}^{-2}$ de canteiro de adubos verdes
(Figura 6). No que se refere aos tipos de adubos verdes, não se observou diferença estatística entre as espécies, com valor médio de 70,0; 65,0 e 66,0 $\mathrm{g} \mathrm{m}^{-2}$ de canteiro, respectivamente (Tabela 2). A massa seca é uma característica não desejável 
pelo consumidor, tendo em vista que o mesmo prefere as folhas de rúcula bastante suculenta. No entanto essa característica é de importância no que se refere ao

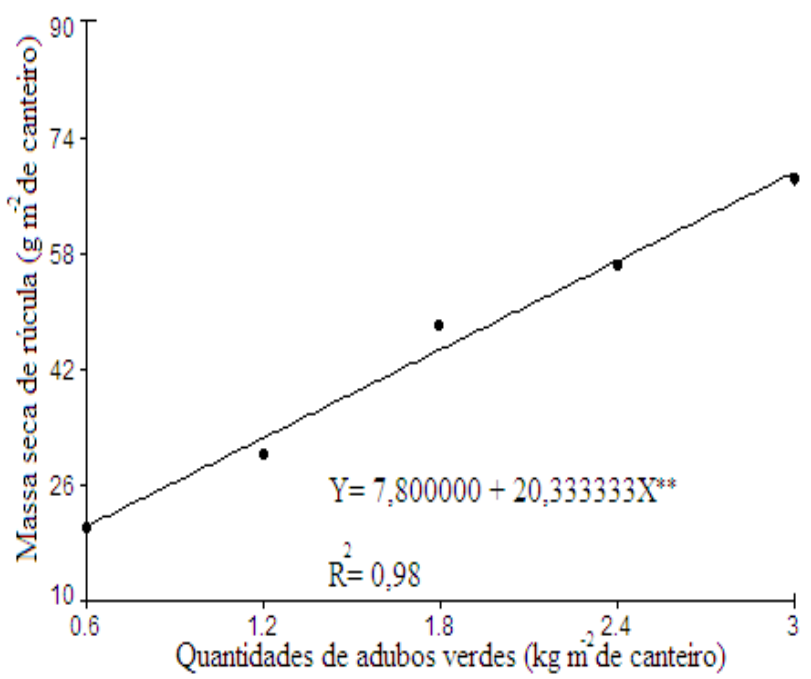

Figura 6. Massa seca de rúcula sob diferentes quantidades de adubos verdes. UFERSA, Mossoró-RN, 2011.

Tabela 2. Altura (AT), número de folhas (NF) e matéria seca (MS) de rúcula sob o efeito residual de diferentes quantidades e tipos de adubos verdes. UFERSA, Mossoró-RN, 2011.

\begin{tabular}{lccc}
\multicolumn{1}{c}{ Tipos de adubos verdes } & AT $(\mathrm{cm})$ & $\mathrm{NF}$ & $\mathrm{MS}\left(\mathrm{g} / \mathrm{m}^{2}\right)$ \\
\hline Jitirana (Merremia aegyptia L.) & $20,6 \mathrm{a}$ & $10,8 \mathrm{a}$ & $70 \mathrm{a}$ \\
Flor-de-seda (Calotropis procera) & $18,4 \mathrm{~b}$ & $10,0 \mathrm{~b}$ & $65 \mathrm{a}$ \\
Mata-pasto (Senna uniflora) & $18,2 \mathrm{~b}$ & $10,0 \mathrm{~b}$ & $66 \mathrm{a}$ \\
\hline Médias dos adubos verdes & 19,1 & 10,3 & 0,67 \\
\hline CV $(\%)$ & 09,3 & 11,3 & 10,3 \\
\hline
\end{tabular}

" Médias seguidas de letras diferentes na coluna diferem entre si ao nível de 5\% de probabilidade pelo teste de Tukey.

Tabela 3. Desdobramento dos tipos de adubos verdes dentro das quantidades de adubos verdes na massa fresca de rúcula. UFERSA, Mossoró-RN, 2011.

\begin{tabular}{cllcccc}
\hline Característica & \multicolumn{1}{c}{ Tipos de adubos verdes } & \multicolumn{4}{c}{ Quantidades de adubos verdes $\left(\mathrm{g} \mathrm{m}^{-2}\right.$ de canteiro) } \\
\cline { 3 - 6 } & & 0,6 & 1,2 & 1,8 & 2,4 \\
\hline \multirow{2}{*}{$\begin{array}{c}\text { MFR } \\
\left(\mathrm{g} / \mathrm{m}^{2}\right)\end{array}$} & Jitirana (Merremia aegyptia $\mathrm{L})$. & $320 \mathrm{a}$ & $380 \mathrm{a}$ & $430 \mathrm{a}$ & $560 \mathrm{a}$ & $690 \mathrm{a}$ \\
\cline { 2 - 7 } & Flor-de-seda (Calotropis procera) & $260 \mathrm{~b}$ & $320 \mathrm{~b}$ & $360 \mathrm{~b}$ & $430 \mathrm{~b}$ & $600 \mathrm{~b}$ \\
\cline { 2 - 7 } & Mata-pasto (Senna uniflora) & $220 \mathrm{~b}$ & $320 \mathrm{~b}$ & $350 \mathrm{~b}$ & $440 \mathrm{~b}$ & $610 \mathrm{~b}$ \\
\hline
\end{tabular}

* Médias seguidas da mesma letra na coluna não diferem entre si pelo teste de Tukey, ao nível de 5\% de probabilidade.

Tabela 4. Desdobramento dos tipos de adubos verdes dentro das quantidades de adubos verdes no número de molhos de rúcula. UFERSA. Mossoró-RN. 2011.

\begin{tabular}{|c|c|c|c|c|c|c|}
\hline \multirow[t]{2}{*}{ Característica } & \multirow[t]{2}{*}{ Tipos de adubos verdes } & \multicolumn{5}{|c|}{$\begin{array}{l}\text { Quantidades de adubos verdes }\left(\mathrm{Kg} \mathrm{m}^{-2} \mathrm{de}\right. \\
\text { canteiro) }\end{array}$} \\
\hline & & 0,6 & 1,2 & 1,8 & 2,4 & 3,0 \\
\hline \multirow{3}{*}{$\begin{array}{c}\text { Molhos } \\
\left(\mathrm{m}^{2} / \text { canteiro }\right)\end{array}$} & Jitirana (Merremia aegyptia L.) & $2,5 a$ & $2,9 a$ & $3,3 \mathrm{a}$ & $2,8 \mathrm{a}$ & $5,3 \mathrm{a}$ \\
\hline & Flor-de-seda (Calotropis procera) & $2,0 \mathrm{~b}$ & $2,5 b$ & $2,8 \mathrm{~b}$ & $3,3 \mathrm{~b}$ & $4,6 \mathrm{~b}$ \\
\hline & Mata-pasto (Senna uniflora) & $1,7 \mathrm{~b}$ & $2,5 b$ & $2,7 \mathrm{~b}$ & $3,4 \mathrm{~b}$ & $4,7 b$ \\
\hline
\end{tabular}

* Médias seguidas da mesma letra na coluna não diferem entre si pelo teste de Tukey, ao nível de 5\% de probabilidade.

\section{CONCLUSÕES}

Houve interação dos fatores estudados para massa fresca de rúcula e número de molhos.

$\mathrm{O}$ efeito residual na quantidade de $3,0 \mathrm{~kg} \mathrm{~m}^{-2}$ de canteiro contribuiu para a massa fresca de rúcula da ordem de 762 ; 684 e $713 \mathrm{~g} \mathrm{~m}^{-2}$ de canteiro, equivalente a 6,$0 ; 5,0$ e 5,0 molhos de rúcula para jitirana, flor-de-seda e mata-pasto, respectivamente.
Jitirana, flor-de-seda e mata-pasto são espécies promissoras para ser utilizadas como adubo verde na produção de hortaliças.

\section{AGRADECIMENTOS}

Ao Grupo de Pesquisa Jitirana, comprometido com o estudo de espécies espontâneas da caatinga jitirana (Merremia aegyptia); flor-de-seda (Calotropis procera) e mata-pasto (Senna uniflora e Senna Obtusifolia)\} e à UFERSA - 
Mossoró/RN, por oferecerem aparato físico para o desenvolvimento dos trabalhos.

\section{REFERÊNCIAS BIBLIOGRÁFICAS}

CARMO FILHO, F. do; ESPÍNOLA SOBRINHO, J.; MAIA NETO, J. M. Dados climatológicos de Mossoró: um município semiárido nordestino. Mossoró: ESAM, 1991, 121p. (Coleção Mossoroense, série C, 30).

EMBRAPA. Centro Nacional de Pesquisa de Solos. Sistema brasileiro de classificação de solos. Brasília: Embrapa Produção de Informação. Rio de Janeiro: Embrapa Solos, 2006. 306 p.

FILGUEIRA, F. A. R. Novo Manual de Olericultura: Agrotecnologia moderna na produção e comercialização de hortaliças. Viçosa: UFV. 2008. 402 p.

FONTANÉTTI, A.; CARVALHO, G. J. de; MORAIS, A. R. de; ALMEIDA, K. de; DUARTE, W. F. Adubação verde no controle de plantas invasoras nas culturas de alface americana e de repolho. Ciência e Agrotecnologia, Lavras, v. 28, n. 5, p. 967- 973, 2004.

HENRIQUES, G. P. de S. A; LINHARES, P. C. F.; SOLANO, B. de O.; PAULINO, R. da C.; PEREIRA, M. F. S.; Efeito residual da flor-de-seda (Calotropis procera (Aiton) W. T. Aiton) no desempenho agronômico do rabanete. 2011. In: VII CONGRESSO BRASILEIRO DE AGROECOLOGIA. Anais... Fortaleza, v.6, n.2, ISSN 2236-7934.

JANDEL SCIENTIFIC. Table curve: curve fitting software. Corte Madera, CA: Jandel Scientific, 1991. 280 p.

KRONKA, S. N.; BANZATO, D. A. Estat: sistema para análise estatística versão 2. 3. Ed. Jaboticabal: Funep, 1995. $243 \mathrm{p}$.

LINHARES, P. C. F.; OLIVEIRA, J. D. de; PEREIRA, M. F. S.; FERNANDES, J. P. P.; DANTAS, R. P. Espaçamento para a cultura do coentro adubado com palha de carnaúba nas condições de Mossoró-RN. Revista verde, Pombal, v.9, n.3, p.01 - 06, 2014.

LINHARES, P. C. F. Adubação verde como condicionadora do solo. Revista Campo e negócios, Minas Gerais, v.11, n.127, p.22-23, 2013.

LINHARES, P. C. F.; PEREIRA, M. F. S.; HENRIQUES, G. P. S. A.; MARTINS, M. de L.; OLIVEIRA, B. S. de; BEZERRA, A. K. de H. Produção orgânica do coentro em sucessão a cultura da beterraba fertilizada com jitirana. 2012a. In: CONGRESSO BRASILEIRO DE OLERICULTURA, 52. Anais... Salvador: ABH, v.30, 5380-5387.

LINHARES, P. C. F.; SILVA, M. L. da; BEZERRA, A. K. DE H.; SILVA, J. dos S.; SILVA, U. L. da. (2009a) Avaliação da decomposição da jitirana em cobertura no desempenho agronômico de rúcula. Revista Caatinga, Mossoró, v.22, n.3, 1983 -2125, 2009.
LINHARES, P. C. F.; SILVA, M. L. da; BORGONHA, W.; MARACAJÁ, P. B.; MADALENA, J. A. da S. (2009b) Velocidade de decomposição da flor-de-seda no desempenho agronômico da rúcula cv. Cultivada. Revista Verde, Mossoró, v.4, n.2, p.46 - 50, 2009.

LINHARES, P. C. F. 2009. Vegetação espontânea como adubo verde no desempenho agroeconômico de hortaliças folhosas. Tese (Doutorado em Agronomia: área de concentração em Agricultura Tropical), Universidade Federal Rural do Semi-árido, Mossoró, 2009, $109 f$.

REGHIN, M. Y.; OTTO, R. F.; OLINK, J. R.; JACOBY, C. F. S. Efeito do espaçamento e do número de mudas por cova na produção de rúcula nas estações de outono e inverno. Ciênc. Agrotec. Lavras, v.29, n.5, p.953 - 959, set./out., 2005.

SILVA, J. K. M.; OLIVEIRA, F. A.; MARACAJÁ, P. B.; FREITAS, R. S.; MESQUITA, L. X. 2008. Efeito da salinidade e adubos orgânicos no desenvolvimento da rúcula. Caatinga 21: 30-35.

SILVEIRA, P. M.; BRAZ, A. J. B. P.; KLIEMANN, H. J.; ZIMMERMANN, F. J. P. Adubação nitrogenada no feijoeiro cultivado sob plantio direto em sucessão de culturas. Pesquisa Agropecuária Brasileira, v.40, p.377-38, 2005.

SILVESTRE, M. A.; GOMES, M. V.; SANTOS, S. L.; SOUSA, T. P.; LINHARES, P. C. F.; FERNANDES, D. Desempenho agronômico do coentro fertilizado com mata-pasto. ACSA - Agropecuária Científica no SemiÁrido, v.8, n.4, p 55-59, 2012.

SOLINO, A. J. S.; GALVÃO, R. O.; FERREIRA, R. L. F.; ARAÚJO NETA, S. E.; NEGREIRO, J. R. S. Cultivo orgânico de rúcula em plantio direto sob diferentes tipos de coberturas e doses de composto. Revista Caatinga, v.23, p. 18-24. 2010.

SOUSA, J. da S. 2014. Jitirana, flor-de-seda e mata-pasto como fonte de adubo verde na produtividade do coentro. Dissertação (Mestrado em Agronomia: Sistemas Agroindustriais), Universidade Federal de Campina Grande, Pombal, 2014, 44f. 